always does so in the first jear; many of them recur in six months.

I agree that in selected cases the operation is very valuable, and if there is doubt in a case as to removal, the benefit of the doubt should be on the side of operation. I may mention a case in illustration of this point. One of my old pupils at St. Bartholomew's Hospital was in the Indian Medical Service. He had an obstruction, and was operated upon by Major Bird, of Calcutta, for complete obstraction; colotomy was done. By passing his finger he could feel what he believed to be malignant disease. Bat owing to the hot weather the patient was advised to come to England for further treatment, and so consulted me. By passing my finger down the colotomy opening, I could feel a growth of considerable size down the pelvis the examination being made under an anaesthetic. It felt so fixed that when the patient came out of the ansesthetic I explained to him that I could hardly advise its removal. The patient replied that I probably had in my mind that death might occur at the operation, but that he did not mind dying under the operation, but dreaded dying from cancer. He added that he would take the fall responsibility for his life if I would attempt the removal.

I did the operation in St. Bartholomew's Hospital, and it was the worst I ever did. It occupied two and a hall hours. The growth was not anatomically fixed, but was tirmly set in adhesions deep in the pelvis. I removed a mass as large as my fist, with six or seven inches of bowel, and I never knew a patient who so nearly died. For fortyeight hours there was no sign of any palsation at the wrist. His friends came, and I told them the patient was going in an hour or two. Bat the patient whispered he was not going to die, and he did not. Only a short time ago I had a letter from him from India, which was dated as his eighth birthdey, for he dated his life from the operation. He sent me an il-ft. tiger skin and his comment was:

I send you this tiger skin to show that I am in perfect health and I have not lost my nerve, for I shot this animal in one of the wildest parts of India, and I shot it on foot.

This case makes it clear that in such a disease it is well to err on the side of doing too much rather than too little. Believing, as I firmly believe, that a number of these cases are carable if operated apon early, it is a pity that practitioners do not spend more time in the study of the symptoms of rectal cancer, for they are obvious. Never. theless, time after time cases come to me which have been treated for long periods as chronic dysentery, intestinal catarrb, piles, etc., without any examination having been made, whereas if that simple precantion had been taken, the nature of the disease would have been early apparent, and they might have been treated by operation with permanent success instead of having drifted into a hopeless condition.

I think we are greatly indebted to Mr. Edwards for the admirable way he has stated bis facts and brought the whole subject so concisely before us.

\section{A NOTE ON THE}

\section{TREATMENT OF RHEUMATOID ARTHRITIS BY VACCINES.}

BY

GILBERT A. BANNATYNE, M.D.Glasg., F.R.C.P.Edin., PHYSICLAN TO THE ROYAL ONITED AND MINERAL WATER HOSPITALS, BATH,

AND

JAMES LINDSAY, M.D.Edin., M.R.C.P.Lond.,

PATHOLOGIST, LATE RESIDENT MEDICAL OFFICER, ROYAL MINERAT WATER HOSPITAT, BATH.

For some time past the systematic examination of the blood in cases of acute rheumatoid arthritis has been carried out in the laboratory of the Royal Mineral Water Hospital, and in certain cases micro-organisms have been isolated and raccines prepared.

The following is the history of two such cases, and the results have been so exceedingly satisfactory that we are encouraged to hope that in vaccines a cure may be found for many acute cases of rheumatoid arthritis.
CASE I.

J. M., female, aged 44, nurse. Was quite well till March, 1909 The frat symptom was a throbbing pain in the proximal interphalangeal joint of the index finger of the left hand. This pain continued off and on (no other joint being affected) till June 1909, when the left foot became very painfal, inflamed, and swollen. She was, however, still able to walk and remained on duty as a hospital nurse till November, when the right foot also became swollen and inflamed. She was now unsble to walk. The joint seemed to be more swollen at night than during the The joint seemed to be more swollen at night than during the daytime, and there was slight oedema. She remained confined to bed till February, 1910, when she went to the south coast. Weriod to stand on her feet. Soon, however, she becsme worse period to stand on her feet. Soon, however, she became worse, till the finger-joints, knees, ankles, hips, shoulders, and cervicad
joints were involved in quick succession. Ultimately she joints were involved in quick succession. Ultimately she knees, or feet, and she conld not feed herself. In May she came to Bath, where she was under treatment nine weeks, vapour and other bsths being given. She was no better at the end of that time. On Jaly 14th she was admitted to the Rojal Mineral Water Hospital. On examination she presented all the features of acute rheumatoid arthritis. All the joints were affected. Evening temperature did not rise above $99.2^{\circ} \mathrm{F}$. There was no albumis album had an attack of influenza six years previous to the onset of the joint symptoms. There was no family history of joint troubles.

On Angust 6th she had her first injection of fibrolysin. This was repeated every fourth day till nine injections had been given. She was also having the thermal baths, bat up to September 12th there was no improvement whatever, and she lay in bed with her knees drawn up, unable to move and unable to feed herself. On that date her blood was found to contain a micro-organism, and a vaccine was prepared and injected. The dose used was $5,000,000$ throughout. The injections were given sub. cataneously every third day. There was never any rise in temperature or other constitational distarbance, but after the first and second injections she experienced a conniderable amount of pain in the joints. From that time a rapid and continuous improvement took place in her general cundition. The pains in the joints became much less; movement of the joints was speedily obtained, till, at the end of seventeen injections, she was able to move her head freely, feed herself, knit, and walk up and down stairs without assistance.

\section{CASE II}

H. M. B , female, aged 41, married, was admitted to the Royal Mineral Water Hogital on Angust 13 th 1910 . The onset of the condition, which occurred four months after a confinement, condition, which occurred four months after a confnement, began ten years previously with generalized joint pains. On admission the case was seen to be a typical one of rheumatoid arthritis. There was no evening rise of temperature above
$99^{\circ}$. F. There was no albumen. The proximal interphalangeal joints of the fingers were fusiform, and the synovial membrane was thickened and pouched. The wrists, elbows, shoulders, knees, and temporo-maxillary joints, which had all been acutely affected, were in a subacute or chronic stage. There was a hands, also of the muscles of the forearms, thighs, and legs.

In addition to the thermal waters which the patient was having on September 5th, she was given guaiacol carbonate gr. v. t.i.d. On September 15th there had been no improvement in the condition of the patient and on this day a culture was obtained from the patient's own blood, and a vaccine prepared. Injections of 5,000,000 were given on alternate days. There was no rise in temperatare after any of the eleven injections given. Immediately following on the administration of the second dose the patient lost practically all her joint pain. After three or four doses she was able to move her joints more freely than she had been since the onset of the condition. She improved steadily and continuously till she left hospital.

In both cases the micro.organisms were obtained from blood taken from the veins of the antecubital fossa of the arm, after every precaution had been taken to ensure the impossibility of skin contamination. The media on which the cultures were obtained was blood agar, and during the period of growth the incubator registered $35^{\circ} \mathrm{C}$.

- In Case I a growth was observed on the third evening, the appearance of the colonies being that of semi-trans parent points. The appearance microscopically was that of a diplococcus aggregated in clustere. The stain was retained after employing Gram's method.

In Case II a growth was observed on the second evening in the lorm of single colonies less transparent than in the 
above-mentioned case. These colonies became more abundant twelve hours later.

Microscopically the organism was found to be a micrococcus arranged in clusters. The mioro-organisms were Gram-posibive.

\section{THE PROPOSED CORONERS BILL.} BY

JOSEPH GRIFFITHS, M.A., M.D., F.R.C.S., SURGEON TO ADDENBROOKE'S HOSPITAL.

The following has been written in the hope that it may help to formulate opinion in the medical profession upon the proposed Coroners Bill, which, it appears to me, demands from medisal men a close study as to its pro. visions and a clear insight as to its probable effect upon them, the pablic, and the State.

In spite of the fact that the proposed Coroners Bill was accepted, approved, and, one might almost say, blessed, at the last Annual Meeting of the British Medical Associa tion held in London, it may be well, now that there will of necessity be some time to wait before it can be presented to the Houses of Parliament either in its present or in an amended form, to review its main provisions, and to see how they would alter what is the present custom and how they would affect the doctor.

This proposed bill natarally divides itself into two parts -namely, the one which deals with the coroner, his appointment and fanction; and the other which deals with the certification of death.

The first part of the bill may be dismissed with only a reference to the conditions of appoint ment of a coroner for that is the only part that intimately concerns us.

It is generally well known that medical men have from time to time expressed their dissatisfaction with the way in which some coroners interpret their daties, and with the inefficiency of some owing to a lack of even a rudi. mentary knowledge of medicine. $A s$ is well known, a coronership need not be confined to the members of the two professions of law and medicine, for any one with sufficient knowledge, if adjudged a fit and proper person, may be appointed. In practice, however, this old office is now held either by a doctor or a lawyer-in the majority of instances by a lawyer-and the appointment once made is for life.

Medical men maintain that a coroner should possess not only a rudimentary knowledge of medicine, but a considerable acquaintance with it, because the work is often of such a nature that it can only be properly interpreted by a medical man, and that all a man with such a training requires is an elementary course of instruction, not in law, but in dealing with evidence and how to sift it. A lawyer thinks his knowledge of law is all that is required, and that any medical evidence he may need will be forthcoming by the summoning of a medical man to attend. Now, in the proposed bill the appointment is to be given to a barrister or lawyer of five years' standing or to a doctor with a degree in law, or one registered as a barrister or lawyer. The law man's attitude is upheld-the doctor's is disregarded. The doctors' complaint about coroners was and is now made, not in their own interests, but in that of the public. Our suggestion is that all coroners under the present régime--be they lawyers or barristersshould possess before appointment at any rate an elemen tary knowledge of medicine in all its branches; bat the lawyers have up to the present prevailed, for what is in the bill amounts practically speaking to this-all coroners must be lawyers or barristers, and if one be a doctor in addition, all well and good. The doctor, who has almost invariably daring the bistory of this important office made an exemplary coroner, is in the fature to possess either a degree in law or be a barrister or lawyer. The barrister or lawyer has only to show he has been in practice for a period of five years, whereas the doctor must, in addition to his professional attainments, gain a degree in law-perhaps the easiest way to qualify. Thus an additional burden is thrown upon the doctor and practically none upon the lawjer. The doctors confess in theic innocence a know. ledge of law would be of advantage to them in acting as coroners, but the lawyers are self-sufficient, and consider themselves quite equal to the work, even if they be ignorant, as some of them can be, of any medical knowledge. If the medical profession be content with the pro. posed alteration it can be of but little use to draw attention to the distinction of treatment meted out to the doctors and lawyers in this new bill. I, for one, will be sorry to think that our successors may, and with justice, say we were sold at such and such a date-meaning the paseing of this or a similar Coroners Bill. If the legal profession is the stronger, let us submit for the present to our luck, bad as it may be, but let as not acknowledge that the lawyers are in the right, for the sake of the community.

\section{Certificate of Deate.}

The conditions for filling up a certificate of death at the present time places no other obligation upon the doctor than giving to the best of his ability the cause or causes of death. The information as to the death, the identifica. tion of the body, and the fact that the person is dead, are all given to the doctor by the informant, and it is no part of his duty to investigate one or all of them. All he does is to fill up the form and hand it to the applicant, who takes it to the registrar in order to obtain a barial certificate. Accordingly, some one who knows the person, and who knows he or she is dead, applies to the doctor, who certifies to the cause or causes of death, so far as he knows them; there the duty of the doctor ende, and this service he rendere, by compulsion, it is true, to the State free of charge.

Under the present proposal, as embodied in the bill, notice of the death is not to be sent to the doctor. But, within twenty-four hours of the death of a person, the doctor must proceed to view the body and then to identify it, see it is actually dead, and then fill up and sign the certificate and post it to the registrar. Thue, in ajdition to filling up the certificate free of charge to the State as formerly, he is further compelled to see that it is So-and so, that he is dead, and then to duly post the certificate to the registrar. The inspection of the body of a dead person is made for two purposes, at any rate-(a) to identify the person, and $(b)$ to see that he or she is actually dead. Identification of the body is very important, and so is the examination of the body with the view of seeing whether life is extinct, and in a well-regulated State reasonable means ought, we would all agree, be taken to ensure this being done.

First, as to the identification of a corpse. Who is in a position to identify the body of a dead person? Not the doctor, not the police, no one except the relatives or person who lived with and knew the decessed. The doctor is not asked in a coroner's court to identify the body, for a very good reason. An inspection of a dead body by a doctor would be of no more value than an inspection by a stranger, except in places where the doctor is familiar with his former patient. In big towne, for example, an inspection by the doctor called in casually perhaps, could be of little, if any, value, and in small towns and in the country it would be superfluous and lead to nothing bat vexation to the relatives and to the doctor.

Secondly, as to evidence of death. Judging from the number of cases in which there is genuine fear of being buried alive, it is necessary that doctors should regard the subject seriously. To determine whether a person is dead or alive is no easy matter; mere inspection of a body, feeling whether it is warm or cold, trying to count or detect the respiratory movements or the cardiac impulses, are all uncertain and not worthy of consideration, if the object be to determine actually whether life be extinct or not. So far as I can gather, it is necessary to perform sometbing that will revive the ordinary signs of life without any dabiety, and yet such as will not interfere in any way with complete restoration to life should it be present. Venesection, as commonly performed fifty years ago, would, I think, serve the purpose, because it would certainly wake the person up, and would not in any way interfere with complete restoration to life. Every doctor could perform the operation, and no one need be buried alive provided some one or the State directs that such an operation of skill be carried ont.

Therefore, in connexion with identification, the doctor will be of little value; but in order to make sure a pereon is actually dead a doctor must be employed, and he must by some means make sure in each case; indeed, he must 